formity. Here the pains are most extreme, and vary in intensity according to the health of the individual. Of course lemon-juice cannot here be expected to benefit the patient, though its credit as a remedy has often suffered owing to its administration in such pseudo-rheumatic cases.

\section{ON THE USE OF CHLOROFORM IN A CASE OF INFANTILE CONVULSIONS.}

Bу W. C. WILLIAMSON, M.R.C.S.L.,

PROFESSOR OF ANATOMX AND PHYSIOLOGY IN OWEN'S COLLEGE, MANCHESTER.

Srive it is important that all examples of the application of a new remedy should be placed on record, whether the result has been successful or not, the following case, in which a young infant was kept under the influence of chloroform for a period of sixty hours, merits publication.

Mrs. R- was confined of a fine male child, March 19 th Some little time after her confinement both her breasts became the seats of mammary abscess, hence the infant was compelled to have recourse to artificial food, which, however, did not appear to disagree with it. On Friday morning, April 29, it was seized with a slight convulsion, which recurred on the evening of the same day, and, during the three subsequent days, it suffered from three or four fit daily, each attack continuing about twenty minutes. The fits gradually became more severe; some continued three or four hours without remission, though not very violent; others, which usually woke him up from sleep, when he uttered a sharp scream, were much more severe, though of shorter duration. Of these latter ones the child appeared to have an instinctive dread. Ultimately the fits were unceasingly present whenever the child was awake. During the first two or three days the child's bowels were a little confined, and afterwards the motions became rather slimy and greenish, but no obvious source of irritation could be detected. There was no feverishness or heat of head, except during the more violent fits, and even then the scalp was less hot than might have been anticipated at the commencement. The Fontanelle was neither raised or depressed, but towards the end of the convulsive attacks it became decidedly depressed.

The congestion and lividity produced by the fits gradually increased, and, owing to the difficulty of giving nourishment, the child soon began to lose flesh. The quick succession of the convulsions sometimes made it impossible to give food for twelve hours together.

A leech was applied to the temple, warm baths employed mild alterative doses of mercury with chalk and compound ipecacuana powder, administered internally, along with other remedies calculated to allay irritation and remove any irritant likely to be lodged in the bowels; but none of these remedies appeared to have the slightest influence either for better or worse. Under these circumstances, since the child was rapidly sinking, Dr. Bardsley and myself determined to have recourse to chloroform. I commenced the use of it at nine $0^{\prime}$ clock on the evening of Friday, May 8 th. The child was then in a violent convulsion, which had continued for severa hours. I folded a thin muslin handkerchief into a hollow funnel-shaped form, and after dropping half a drachm of chloroform into the hollow cavity, I inverted it over the nose of the convulsed infant, holding it about an inch from the face, so as to allow a free current of air to reach the respiratory organs. In about two minutes the convulsion gave way, and the child went to sleep. The effect of the chloroform passed off in a fer minutes, when it was again applied, and thus the child was kept quiet for some hours.

I soon found that by slightly releasing the infant from the influence of the chloroform, but without allowing the convulsions to regain their power, it was possible to give a supply of food, which was swallowed eagerly and with great facility. This alone was an important advantage gained from the chloroform, since previous to its administration the child was obviously sinking from inanition.

For some hours I administered the chloroform myself, but afterwards entrusted it to an intelligent nurse, who was instructed to apply it the moment the child exhibited any movements indicating returning consciousness. This treatment was continued without a moment's interruption, until nine o'clock on the subsequent Monday, when the use of the chloroform was suspended, the infant having then been under its influence sixty hours, sixteen ounces having been used. Its appearance was now decidedly improved; its flesh was more firm, and the sunken eye and livid countenance were exchanged for a much more healthy aspect. The convulsions exhibited no disposition to return, and up to the present period (May 30) the infant has enjoyed perfect health.

In this case $I$ have not the slightest doubt that the chloroform was instrumental in saving the patient's life; I can scarcely conceive recovery to have been possible without its aid. No injurious effects, however trivial, appeared to accrue from its use, and I am satisfied that, if necessary, we could have employed it for a much longer period without evil consequences.

It is of course important to ascertain to what class of convulsive attacks this new remedy is applicable. In the present instance, though the condition of the patient was masked at its commencement, in its latter stages the disease assumed the adynamic type. It is obviously in such cases that we should be most likely to obtain benefit from the combination of the stimulating and sedative properties of the anæsthetic agent. It is a curious circumstance that such a modified use of it as allowed of the action of the muscles of deglution, was nevertheless sufficient to control the convulsions.

June, 1853.

\section{OBSERVATIONS ON THE LATE ENDEMIC FEVER AT CROYDON.}

By GEORGE BOTTOMLEY, Esq., F.R.C.S.

I CONSIDER the sanitary measures, as carried out in Croydon, of national importance. The doings of the Croydon Board of Health having been attended with most disastrous consequences to life, health, property and trade, too much publicity cannot be given to them, to prevent other towns from falling into a similar mistake. The Board of Health at Croydon has evidently entertained an erroneous opinion that the medical profession, as a body, are opposed to any and all sanitary improvements. I therefore deem it necessary to remove such a feeling; for, on the contrary, they are desirous and hail with delight any proceeding that will improve the public health. Upon the completion of the tank for the supply of water to the town, a dinner took place at the Greyhound, Croydon, at which forty or fifty gentlemen, principally members of the Board at Croydon and their friends, and some gentlemen connected with the London Board, attended. Upon that occasion there was not a medical practitioner connected with Croydon present. The truth was, that the charge for the dinner was $21 s$, and the medical men of Croydon thought it too much; and, indeed, it appeared to them rather intended to make it exclusive. At that dinner one of the gentlemen from London, in returning thanks for his health having been drunk, alluded to the absence of the medical men of the town, which he said evidently arose from their dislike to sanitary improvements, for it would no doubt remove fever, $\&$ c., and that medical practioners would be at a discount-in short, there would be but little for them to do. The remark was as unfortunate as it was illiberal.

The tubular system of drainage, as carried out in Croydon, has proved a most marked failure from the very commencement to the present time. In order to lay the pipes at the backs of houses, the workmen, there not being an overlooker to direct them, when they came in contact with old drains and cesspools, scattered the contents about, thereby saturating the earth with their contents. When the rain came, accompanied with a high state of temperature, poisonous gases were exhaled from the earth. This with the network of small pipes taking very tortuous courses, occasioning stoppages in all directions, both in the premises of private d wellings, as well as in the public streets; the getting rid of those obstructions, for which the pipes were removed and the contents pumped up into the main streets, and the sewage allowed to find its way along the gutters, throwing off poison as it went, the surface-water drainage allowed to remain undisturbed, and the open gratings pouring forth smells of the vilest character. Not only were the abominations permitted to remain, but their course cut off, and their contents allowed to percolate the earth; and the receptacle for the sewnge is close to the town, and the ditches in its neighbourhood, filled with the sewage, pouring forth more stinks and more poison; and the contents of that receptacle, sold as manure, is carried through the town in the night, and allowed to be put into a hole which is open; so that there were not only one or two causes, but many. These may be thus summed up:-The disturbing of the old drains and cesspools; the escape of sewage in private dwellings, and the pumping of it up into the public streets, arising from the stoppages frequently occurring in the numerous small pipes 